\title{
The Mediatory Role of Exercise Self-Regulation in the Relationship between Personality Traits and Anger Management of Athletes
}

\author{
Somayeh Shahbazzadeh ${ }^{1} \&$ Mohammad Reza Beliad ${ }^{2}$ \\ ${ }^{1}$ Department of Psychology, Shahr-e-qods Branch, Islamic Azad University, Tehran, Iran \\ ${ }^{2}$ Karaj Branch, Islamic Azad University, Karaj, Iran \\ Correspondence: Somayeh Shahbazzadeh, Department of Psychology, Shahr-e-qods Branch, Islamic Azad \\ University, Tehran, Iran.
}

Received: November 8, 2016

Accepted: December 9, 2016

Online Published: April 29, 2017

doi:10.5539/ies.v10n5p181

URL: https://doi.org/10.5539/ies.v10n5p181

\begin{abstract}
This study investigates the mediatory role of exercise self-regulation role in the relationship between personality traits and anger management among athletes. The statistical population of this study includes all athlete students of Shar-e Ghods College, among which 260 people were selected as sample using random sampling method. In addition, the analysis was done using structural equation modeling and path analysis through SPSS and Amous software. The results indicated that in investigating the effect of personality traits on anger management, neuroticism impacts on anger management positively and agreeableness and conscientiousness impact on anger management negatively. In response to the second question, it was concluded that exercise self-regulation impacts on anger management positively, so that with one increase in the standard deviation of exercise self-regulation scores, 0.224 standard deviation is added to anger management. Therefore, in response to the third research question, it was concluded that exercise self-regulation mediates the effect of agreeableness and conscientiousness on anger management significantly.
\end{abstract}

Keywords: personality traits, anger management, exercise self-regulation and athletes

\section{Introduction}

Anger is one of the complex human emotions and is a common reaction to frustration and ill-treatment. Anger is an intense emotional response to deprivation and stimulation that is characterized by the increase of automatic arousal and the change of central nervous system activity (Kendal, 2000). When the confidence and integrity of the person is attacked, anger happens which is a natural response and is fluctuating between mild irritation to intense fury (Thomas, 1998).

In general, it can be said that the effect of weaknesses and shortcomings in anger management is beyond personal discomfort and damage in interpersonal relationship. It leads to public health problems, public incompatibility and aggressive behaviors, and if it is not controlled properly it can prevent optimal functioning and success of individuals, groups and communities (Navidi \& Borjali, 2007).

Many factors may affect the appearance of anger. In general, biological, cultural, environmental factors, interpersonal relationships, academic problems, employment conditions and personality traits or characteristics may lead to anger (ÖZYEŞILL, 2012). Personality traits influence many behaviors and may be associated with many factors. Research has shown that there is a relationship between psychiatric symptoms and anger (Bozkurt \& Cam, 2010). Albayrak and Kutlu (2009) showed that students who describe themselves as aggressor have higher levels of internal and external anger and the students who claim they have low levels of anger experience less internal anger.

In psychological Science, different theories are explained in the context of personality traits and their effects on emotion, thinking and behavior. meantime the Big Five Factor Model of Costa and McCrae is considered as one of the most usable theories of personality in recent years that suggests the personality traits are genetic and fixed and are patterns of thoughts, feelings and behavior. In this model, the character is a multidimensional concept and each dimension is the sum of traits. These dimensions (factors) are: neuroticism, extraversion, openness, agreeableness and conscientiousness (Farahani, 2009). In general, it can be stated that the foundation of neuroticism is negative and unfavorable emotions and experiences. Some of the properties of this factor are 
anxiety, depression, shyness, vulnerability, aggression and violence, emotional instability, sensitivity and irritability. Another variable is exercise self-regulation. Self-regulation is a prominent concept in self-determination theory (Frederick \& Ryan, 1995) and cognitive evaluation theory (Deci \& Ryan, 1985).

This theory is based on the communication chain between internal motivations (e.g. participation in physical exercise due to its inherent rewards) and external motivations (e.g. participation to obtain external rewards such as prizes). All kinds of motivations are characterized by regulatory processes that include values, rewards, self-control, benefits, hobbies and satisfaction. Furthermore, both internal and external motivations are divided into internal self-regulation, external self-regulation, introjected self-regulation, and identified self-regulation.

Self-regulation is an active process in which learners try to adjust and control their own cognition, motivation and behavior (Rahmaniyan, et al., 2014). Exercises self-regulation is the ability of individuals to monitor exercise goals, keep track of progress towards exercise goals and understand personal rewards resulted from exercise behavior (Heider, 2011). Exercise self-regulation is one of the components of emotional intelligence as well as a protective factor that is different in novice athletes and non-athletes (Khalili et al., 2012). According to above questions, it seems that personal traits are predictors of anger management. However, despite numerous studies mentioned about the relationship between personality traits and anger management, the role of mediating factors in this relationship is often neglected. Therefore, this study tries to investigate the role of self-regulation as a mediator of this relationship.

The following questions are proposed in order to study the main purpose of the research.

The first question: Does the impact of personality traits on anger management is significant?

The second question: Does the impact of exercise self-regulation on anger management is significant or not?

The third question: Do personality traits impact on anger management by the mediation role of exercise self-regulation?

\section{Research Methodology}

The method of this study was descriptive-correlational. The statistical population included all athlete students of Shar-e Ghods College (N=260). Sampling method was stratified random method and 260 people were selected to complete the questionnaire. In order to achieve the ultimate goal of research in this study, two following methods were used to collect data:

Library method: to write research theory and literature in this study, different books and domestic and foreign papers and theses have been used. In addition, to enrich literature review and enhance its credibility, internet magazines and websites as well as reputable domestic and foreign references have been used.

Questionnaire: one of the most common methods in field data collection is to use questionnaire which makes possible data collection broadly (Hafeznia, 2009).

Tools used to collect data from the sample are as follows:

- $\quad$ Spielberger's State-Trait Anger expression Inventory (2)

- $\quad$ NEO Five-Factor Inventory of personality (NEO-FFI)

- Exercises self-regulation questionnaire

The present study was conducted at Shar-e Ghods College. After visiting the clubs and selecting subjects, the aim of the study was explained to them. In addition, it was notified to them that the work is a research and the information will be secret. The subjects announced their content to participate in the study. Then they were asked to answer the questionnaires of anger expression styles, NEO-FFI personality traits and exercises self-regulation. After the questionnaires were completed, ultimately they were collected and analyzed.

In order to analyze data, inferential statistics, correlation coefficient, regression analysis, structural equation modeling and path analysis were used through Amous SPSS software.

\section{Findings}

This study used structural equation modeling to answer the questions. In the conceptual model (Figure 1) personality traits impact on anger management both directly and indirectly (through the latent variable of self-regulation). Based on the conceptual model (Figure 1) self-regulation is a latent variable and is measured by its indicators (external self-regulation, introjected self-regulation, identified self-regulation and intrinsic motivation). In addition, anger management is also a latent variable and is measured by anger internal control and anger external control. For this reason and based on the principles of structural equation modeling, it was 
necessary to assess measurement model before testing the structural model. This means that it is required to know to what extent self-regulation and anger management can measure its own latent variables.

\section{Research Measurement Model Test}

In the present study, it was hypothesized that the latent variable of self-regulation is measured by external self-regulation, introjected self-regulation, identified self-regulation and intrinsic motivation and the latent variable of anger management is measured by anger external control and anger internal control. Now the question is that whether the measurement model of present study fits collected data? Whether the observed variables in the study can measure their own related latent variables? In order to answer these questions and test the measurement model, confirmatory factor analysis was performed using AMOS 7.0 software and estimating maximum likelihood (ML). The fit index of Chi-square indicated that the model has an acceptable fit $\left(\chi^{2}(\mathrm{~N}=259\right.$, $\mathrm{df}=8)=4.646, \mathrm{p}=0.795$ ). Given the non-significance of chi-square index, it was concluded that other fit indices support the measurement model fitness with collected data. Table 1 indicates the estimation of unstandardized parameter, standardized parameter, standard error and critical ration for each of the life quality indicators.

Table 1. Measurement model parameters in confirmatory factor analysis

\begin{tabular}{ccccc}
\hline Indicator/latent variable & $\mathrm{b}$ estimation & Standard parameter $\beta$ & Standard error & Critical ratio \\
\hline external self-regulation/self-regulation & 1 & 0.314 & & \\
introjected self-regulation/self-regulation & 0.512 & 0.402 & 0.147 & $3.478^{* *}$ \\
identified self-regulation/self-regulation & 0.436 & 0.590 & 0.112 & $3.907^{* *}$ \\
Internal motivation/self-regulation & 0.828 & 0.757 & 0.216 & $3.853^{* *}$ \\
External control of anger/anger management & 1 & 0.862 & 0.217 & $4.507^{* *}$ \\
Internal control of anger/anger management & 0.978 & 0.776 & & \\
\hline
\end{tabular}

Note. Because the factor loadings related to external self-regulation and external control of anger are stabilized with the number 1 , so their standard error and critical ratios have not been calculated

$\mathrm{P}<0.01^{* *}$

As the above Table shows the least factor loading is related to external self-regulation/ exercise self-regulation (0.314) and the highest loading factor is related to external control of anger (0.862). Generally, the results of above table shows that all the observed variables measure their corresponding latent variable significantly.

\section{Structural Model Test}

After ensuring the ability of indicators in measuring latent variables, research structural model was tested by structural equation modeling. In this model (Figure 1), it is assumed that personality traits impact on anger management both directly and indirectly (through self-regulation). Studying the fit indices resulted from structural model testing showed that chi-square is significant at $0.50\left(\chi^{2}(\mathrm{~N}=259, \mathrm{df}=28)=4.151\right)$. Because of the sensitivity of chi-square index compared to sample size, this index is not appropriate to assess model fitness with collected data. Therefore, other fit indices were studied. The root mean square error of approximation (RMSEA) was equal to 0.05 (it is said that RMSEA less than 0.08 and 0.05 indicates an acceptable and excellent fit with collected data, respectively), the goodness of fit index (GFI) was equal to 0.969, adjusted goodness of fit index (AGFI) was equal to 0.927 and comparative fit index (CFI) was equal to 0.971 (it is said that CFI higher than 0.90 and 0.950 indicates an acceptable and excellent fit with collected data, respectively). Thus, all fit indices of fit supported the appropriate fitness of model with collected data. Table 2 shows total path coefficients, direct or indirect relationship between personality traits, self-regulation and anger management. 
Table 2. Total path coefficients, direct and indirect relationship between personality traits, self-regulation and anger management

\begin{tabular}{|c|c|c|c|c|c|}
\hline Paths & & $\mathrm{b}$ & S.E & $\beta$ & $\begin{array}{c}\text { Significance } \\
\text { level } \\
\end{array}$ \\
\hline \multirow{5}{*}{ Total impact } & Neuroticism/anger management & -0.084 & 0.033 & -0.170 & 0.015 \\
\hline & Extraversion/anger management & 0.062 & 0.043 & 0.115 & 0.137 \\
\hline & Openness/anger management & 0.061 & 0.060 & 0.065 & 0.280 \\
\hline & Agreeableness/anger management & 0.151 & 0.052 & 0.237 & 0.003 \\
\hline & Conscientiousness/anger management & 0.077 & 0.034 & 0.178 & 0.011 \\
\hline \multirow{11}{*}{ Direct impact } & Neuroticism/anger management & -0.095 & 0.045 & -0.191 & 0.006 \\
\hline & Extraversion/anger management & 0.068 & 0.043 & 0.126 & 0.096 \\
\hline & Openness/anger management & 0.019 & 0.065 & 0.020 & 0.806 \\
\hline & Agreeableness/anger management & 0.151 & 0.053 & 0.238 & 0.003 \\
\hline & Conscientiousness/anger management & 0.036 & 0.035 & 0.082 & 0.283 \\
\hline & Neuroticism/self-regulation & 0.022 & 0.022 & 0.094 & 0.232 \\
\hline & Extraversion/ self-regulation & -0.013 & 0.032 & -0.051 & 0.534 \\
\hline & Openness/ self-regulation & $090 / 0$ & 0.054 & 0.202 & 0.010 \\
\hline & Agreeableness/ self-regulation & -0.002 & 0.031 & -0.006 & 0.966 \\
\hline & Conscientiousness/anger management & $089 / 0$ & 0.038 & 0.427 & 0.001 \\
\hline & self-regulation/ anger management & $462 / 0$ & 0.247 & 0.224 & 0.027 \\
\hline \multirow{5}{*}{ Indirect impact } & Neuroticism/anger management & 0.010 & 0.012 & 0.021 & 0.256 \\
\hline & Extraversion/anger management & -0.006 & 0.014 & -0.011 & 0.550 \\
\hline & Openness/anger management & 0.042 & 0031 & 0.045 & 0.036 \\
\hline & Agreeableness/anger management & -0.001 & 0.015 & -0.001 & 0.959 \\
\hline & Conscientiousness/anger management & 0.041 & $024 / 0$ & 0.096 & 0.027 \\
\hline
\end{tabular}

Based on the above table, research questions were answered as follows.

Question 1: does the impact of personality traits on anger management is significant?

According to the findings presented in Table 2, the total impact (the sum of direct and indirect impacts) of neuroticism on anger management is negative and is significant at $0.05(\mathrm{P}<0.05, \beta=-0.170)$. The total impact of agreeableness on anger management is positive and is significant at $0.01(\mathrm{P}<0.01, \beta=0.237)$. In addition, the total impact of conscientiousness on anger management is positive and is significant at $0.05(\mathrm{P}<0.05, \beta=0.178)$. In opposition, the total impact of extraversion and openness on anger management was not significant at 0.05 . Thus, in response to the first research question, it was concluded that neuroticism impacts on anger management negatively and agreeableness and conscientiousness impact on anger management positively.

Question 2: does the impact of exercise self-regulation on anger management is significant?

Table 2 shows that the path coefficient between exercises self-regulation and anger management is positive and significant at $0.01(\mathrm{P}<0.05, \beta=0.224)$. Thus, in response to the second question, it was concluded that exercise self-regulation impacts on anger management positively so that with one standard deviation increase in exercise self-regulation scores, 0.224 standard deviation is added to anger management.

Question 3: Do personality traits impact on anger management by mediation of exercises self-regulation?

Based on Table 2 results, indirect path coefficient between openness and anger management is positive and significant at $0.05(\mathrm{P}<0.05, \beta=0.045)$.Also, the path coefficient between the personality trait of conscientiousness and anger management is positive and significant at $0.05(\mathrm{P}<0.05, \beta=0.096)$.It should be noted that indirect path coefficient of three personality traits including neuroticism, extraversion and agreeableness with anger management was not significant at 0.05 . Thus, in response to the third research question, it was concluded that exercises mediates the impact of openness and conscientiousness on anger management significantly. Figure 4.3 shows the research structural relations in explaining the relationships between personality traits, exercise self-regulation and anger management. 


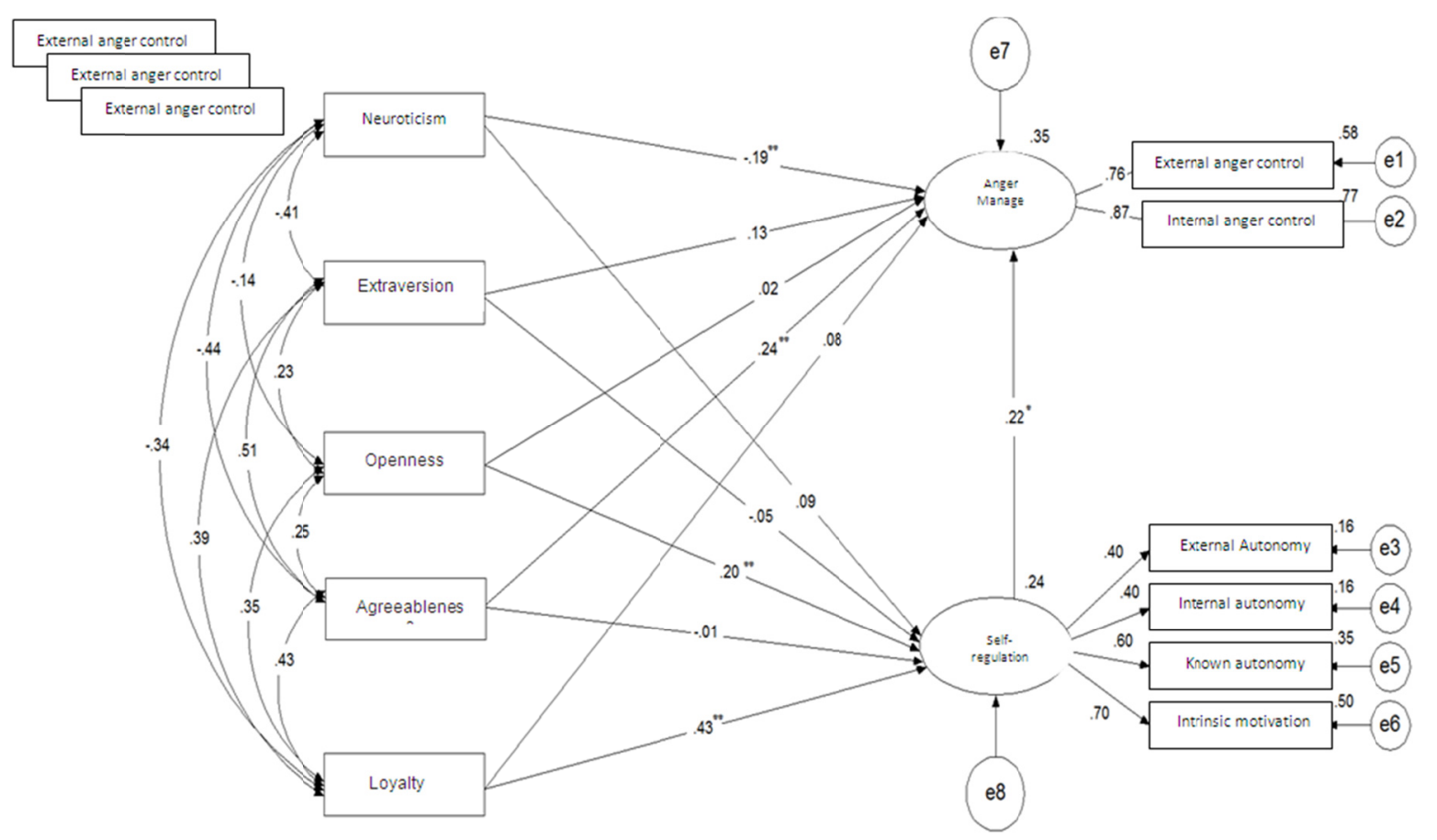

Figure 1. Research structural model in explaining the relationship between personality traits, exercise self-regulation and anger management

\section{Discussion and Conclusion}

Question 1: does the impact of personality traits on anger management is significant?

According to study findings presented in chapter 4, the total impact (total direct and indirect impacts) of neuroticism on anger management is negative and significant at 0.05 . The total impact of agreeableness on anger management is positive and significant at 0.01 .

Also the total impact of conscientiousness on anger management is positive and significant at 0.05 . In opposition, the total impact of extraversion and openness on anger management was not significant at 0.05 . Thus, it was concluded that between personality traits, neuroticism impacts on anger management negatively and agreeableness and conscientiousness impact on anger management positively.

Thus, it can be stated that the high agreeableness and conscientiousness in athletes cause anger management to be done in a better way. In other words, the athletes studied in this research were conscientious, keep their appliances clean, do things with a sense of responsibility, do their work in due time, pay attention to planning and time schedule to get things done.

In opposition, the higher the neuroticism is in athletes, the less anger management happening will happen. This means that no matter how athletes studied in this population are people with less concern, don't underestimate themselves, do not shattered under stress, do not feel stress, have a sense of value and don't have fear and anxiety, the components of anger management such as angry, feeling of frustration, a sense of madness because of anger, aggression, etc., can be managed and controlled.

Consistent with this finding, the results of Pease and Lewis's (2015) research suggested that neuroticism and agreeableness were less associated with anger. Conscientiousness and extraversion were also associated with most of anger components. The results of ÖZYEŞiL's (2012) study showed that all five factors of personality (neuroticism, extraversion, agreeableness, conscientiousness, openness to experience) can predict trait and state anger.

Question 2: does the impact of exercise self-regulation on anger management is significant?

The results of analyzes shows that the path coefficient between exercise self-regulation and anger management is positive and significant at the level of 0.01 . Thus, it was concluded that exercise self-regulation impacts on anger management positively, so that with one standard deviation increase in exercise self-regulation scores, 
0.224 standard deviation is added to anger management. According to the results, it is inferred that the high exercise self-regulation is in athletes, their anger management will be monitored and controlled at higher levels. Thus, it can be inferred that athletes in this study feel good and positive about their exercises, enjoy practicing, exercise gives a sense of being strong, the physical progress is important for them, in some cases they consider practicing as hobby and sometimes as a goal. When above mentioned items are manifested in athletes at higher levels, the issues such as getting angry, feeling of frustration, screaming, aggression, irritability sense, frustration and beating, moodiness, anger, etc., can be monitored and controlled at much greater and better levels. According to the literature, Hoyle (2010) in his research on the relationship between personality and self-regulation, found that there is a significant relationship between personality traits and self-regulation.

Question 3: Do personality traits impact on anger management by the mediation role of exercise self-regulation?

The research findings suggest that indirect path coefficient between personality traits of openness and anger management is positive and significant at 0.05 . Also, the path coefficient between the personality trait of conscientiousness and anger management is positive and significant at 0.05 . It should be noted that the indirect path coefficient related to three personality traits including neuroticism, extraversion and agreeableness was not significant with anger management at 0.05 . Thus, exercise self-regulation mediates the impact of openness and conscientiousness on anger management significantly.

Thus, according to the above analysis associated with "indirect" coefficient between openness and anger management, it can be stated that there is an inverse relationship between these two components. In other words, the athletes participated in this study are not interested in spending their time for imagination, but they are more interested in finding the right path, poetry and artistic works, trying new and foreign foods and discovering the human fate. So long as the above issues are manifested in athletes at higher levels, the cases like getting angry, feeling of frustration, screaming, aggression, irritability sense, irritability, frustration and beating, moodiness, anger, etc., (which are the components of anger management) are less or rarely observed.

In addition, the results indicates that exercise plays a mediating role between the personality traits of openness and conscientiousness on the one hand and anger management on the other hand. In other words, the variables of openness and conscientiousness-that are examples of "personality"- are mediated in coping with the components of "anger management" such as getting angry, feeling of frustration, screaming, aggression, irritability sense, frustration and beating, moodiness, anger and etc. by the components of "exercise self-regulation" such as good feeling of athletes about training, enjoying exercise, feeling strong during training, development and progress during training, considering exercises as a hobby and etc. This result is in line with Pease \& Lewis (2015)'s study which indicates that conscientiousness mediates the relationship between neuroticism and anger management. Stouten et al., (2013) studied the relationship between personality traits and anger management by attention to justice and concluded that whether in terms of justice or otherwise neuroticism and agreeableness are the best predictors of anger. The results of Kuppens and Tuerlinclx (2007) showed that there is a significant relationship between personality traits and anger and personality traits is associated with anger depending on what triggers it.

\section{References}

Albayrak, B., \& Kutlu, Y. (2009). Ergenlerde öfke ifade tarzı ve ilişkili faktörler. Maltepe Üniversitesi Hemşirelik Bilim ve Sanatı Dergisi, 2(3), 57-69.

Bozkurt, S., \& Ç am, O. (2010). Ç al ış an ergenlerde ö fke bile ş enleri ile ruhsal belirtiler aras 1 ndaki ili ş kinin incelenmesi. $N$ ö ropsikiyatri Ar ş ivi, 47, 105-110.

Bushman, B. J. (2002). Does venting anger feed or extinguish the flame? Catharsis, Runination.

Deci, E. L., \& Ryan, R. M. (1985). The General Causality Orientations Scale: Self-determination in Personality. Journal of Research in Personality, 19(2), 109-134. https://doi.org/10.1016/0092-6566(85)90023-6

Farahani, M., \& Alami, M. (2005). Comparison of the five-big personality factor and locus of control in patients with MS and healthy individuals. Journal of Birjand University of Medical Sciences, 12(1), 41-47.

Frederick, C. M., \& Ryan, R. M. (1995). Self-determination in Exercise: A Review using cognitive Evaluation theory. Journal of Exercise Psychology, 26(1), 5-23.

Hafeznia, M. (2009). An introduction to research methods in the humanities. Tehran: Samat.

Haider, T. (2011). Using Social Cognitive Theory to Predict Exercise Behavior among College Students of South Asian Descent at Two Large Midwestern Universities. A Thesis Submitted to the Division of Graduate Studies and Research of the University of Cincinnati in Partial Fulfillment of the Requirements for the 
Degree of Master of Public Health in the College of Education, Criminal Justice \& Human Services.

Haider, T. (2011). Using Social Cognitive Theory to Predict Exercise Behavior among College Students of South Asian Descent at Two Large Midwestern Universities. A Thesis Submitted to the Division of Graduate Studies and Research of the University of Cincinnati in Partial Fulfillment of the Requirements for the Degree of Master of Public Health in the College of Education, Criminal Justice \& Human Services.

Hoyle, R. H. (2010). Handbook of Personality and Self-Regulation. A John Wiley \& Sons, Ltd., Publication. https://doi.org/10.1002/9781444318111

Kendal, P. C. (2000). Child and adolescent therapy: Cognitive behavioral procedures (2nd ed.). New York: Guilford.

Khalili, S., Zulfikari Zafarani, R., Sharifi, N., \& Malekshahi, M. (2012). A comparison of individual protective factors among female athletes and non-athlete students. Journal of Sport Psychology, 1(1), 36-46.

Kuppens, P., \& Tuerlinckx, F. (2007). Personality traits predicting anger in self-, ambiguous-, and other caused unpleasant situations. Personality and Individual Differences, 42(6), 1105-1115. https://doi.org/10.1016/j.paid.2006.09.011

Navidi, A., \& Borjali, A. (2007). Effects of an anger management program in anger self-regulation skills of high school boys. Psychological Research, 10(3-4), 58-81.

ÖZYEŞIL, Z. (2012). Five Factor Personality Traits as Predictor of Trait Anger and an Expression. Education and $S c, 37,322-333$.

Pease, C. R., \& Lewis, G. J. (2015). Personality links to anger: Evidence for trait interaction and differentiation across expression style. Personality and Individual Differences, 74, 159-164. https://doi.org/10.1016/j.paid.2014.10.018

Rahmaniyan, Z., Vaez-Mousavi, S. D. K., \& Sohrabi, M. (2014). Psychometric properties of the exercise self-regulation questionnaire. Studies of sport psychology, 8, 19-32.

SP (1998). Assessing and intervening with anger disorders. Nurs Clin N Am., 33, 121-33.

Stouten, J., Kuppens, P., \& Decoster, S. (2013). Being angry for different reasons: the role of personality in distributive justice. Journal of Applied Social Psychology, 43, 795-805. https://doi.org/10.1111/jasp.12005

\section{Copyrights}

Copyright for this article is retained by the author(s), with first publication rights granted to the journal.

This is an open-access article distributed under the terms and conditions of the Creative Commons Attribution license (http://creativecommons.org/licenses/by/4.0/). 